\title{
Features of Copyright Transformation in the Information Environment in the Age of Digitalization
}

\author{
Ya. L. Shrayberg ${ }^{a, *}$ and K. Yu. Volkova ${ }^{a, * *}$ \\ a State Public Scientific and Technical Library of Russia, Moscow, 123298 Russia \\ *e-mail: shra@gpntb.ru \\ **e-mail: kv@gpntb.ru
}

Received December 2, 2020

\begin{abstract}
The complexities of transformation of copyrighting in conditions of the intensive use of electronic information and network technologies are considered. Some of the factors that should be taken into account when changing copyright laws are discussed and extensive examples of law modifications and new practices in this area around the world are provided. Attention is paid to the introduction into national copyright laws of separate articles on limitations and exceptions to copyrighting in relation to the work of libraries and educational institutions. It is emphasized that the work on transforming copyrighting in the digital age continues, the balance of interests of society and copyright holders has not yet been achieved, and the rapid emergence of new technologies for the exchange and transmission of information poses new problems. The challenges posed by the coronavirus pandemic are also having an impact on the current discourse on open access to information and copyrighting in works.
\end{abstract}

Keywords: copyright, law reform, copyright limitations and exceptions, cultural heritage institutions, authors' rights, publishing rights, fair use, fair use, orphan works, scientific communications, metadata, open access

DOI: $10.3103 / \mathrm{S} 014768822101007 \mathrm{X}$

\section{INTRODUCTION}

Copyright issues have not left the pages of professional publications in recent decades and the relevance of their discussion is not decreasing, but increasing. As Daniel Gervais, a noted professor of international copyrighting at Vanderbilt University, Nashville, Tennessee, United States stated at the 2019 London Book Fair Charles Clark Memorial Lecture "in the digital environment practically every user of electronic information also becomes an author, so copyrighting becomes important not for a few, but for everyone" [1].

Intellectual property is the result of the creation of the human mind. Copyright is the intellectual property right (exclusive right) of the creator to the results of his work, which are works of science, literature, and art, as well as to personal moral rights.

The author of the work owns the following rights:

- exclusive right to a work;

- copyright;

- the author's right to a name;

- the right to inviolability of the work;

- the right to publish the work.

Copyrighting covers a wide range of works: books, music, paintings, sculptures, films, computer programs, databases, advertisements, maps, and drawings. Copyrighting is a complex issue, especially in today's digital age, and different parties each advocate different points of view. Authors, publishers, digital content producers, large tech companies, the recording industry, cinema, politicians, and finally, and libraries are all part of the ongoing copyright transformation process.

Striking a balance between the public interest and the rights of authors and copyright holders is key. All intellectual property rights are not just an economic contract between publishers and authors/consumers, but also a social contract between publishers and the state. Intellectual property deals with private rights, but they are structured in such a way that they are of public benefit.

Changes in the external environment, namely, the widespread dissemination of electronic publications and network technologies that have occurred in recent decades, bring copyright problems to the fore.

The availability, ease of copying, and distribution of electronic information has created a new public need for access to this information at any time and in any place, which is undoubtedly a blessing, but often conflicts with someone's copyright for the product.

Many people now believe that copyrighting is hindering the political, economic, and social trends of the 21st century: 
- in relation to digital technology, copyrighting hinders innovation, it is too slow, cumbersome, and bureaucratic to use in our barrier-free world of speed, immediacy, and interconnectedness;

- in relation to the consumer, copyrighting prevents people from enjoying their rights to learn, exchange, create, collaborate, and form networked communities.

Taking the public interest of free access to information into account when revising copyright legislation usually occurs either by introducing special exceptions, usually educational, in the text of laws, or by applying the concept of fair use of copyrighted works. However, we would immediately like to warn against the narrow understanding of the public interest. Free access to information and knowledge, which is primarily provided by libraries, is an unconditional blessing. However, it is important to provide a working model that stimulates the creation of new valuable knowledge and allows its creators to receive fair rewards. In general, it is difficult to remain neutral when covering the transformation of copyrighting in the digital age; each of the interested parties has their own interests and defends their case. The balance of interests has not yet been found and this forces us to return to the discussion of copyrighting again and again.

\section{REVISION OF COPYRIGHT LEGISLATION IN THE DIGITAL AGE}

Recognizing the inconsistency of old copyright laws with the new conditions, national governments, copyright holders, civil society organizations, libraries, and other stakeholders are engaging in debate and planning or are already reviewing copyright laws.

Here are some examples.

In Canada, after the 2012 reform (Copyright Modernization Act) copyrighting remains a problem for the community of copyright holders. The reform resulted in heavy losses for Canadian publishers and authors, as it encouraged the reuse of materials in the education sector without paying any remuneration to copyright holders. Virtually all Canadian provincial school boards and education departments have filed lawsuits against the Collective Management Society on the problem of compensating payment for licenses. Recently, the government of Canada launched a process of reviewing and possibly revising the latest changes in copyrighting, but thus far there are no results, as there is no political will to change the situation [2].

In the United States, efforts to adapt copyrighting to technological innovation are not slowing. After 10 years of copyright litigation in the United States, tough lines of resistance have emerged, with strong lobbying support from both sides. On the one hand, content rights industries, including publishers, are unhappy with the expansion of fair use by the American legal system of copyrighted works in the digital age, which they see as a shift in rights from creators to the technology sector. The technology sector, supported by the library community and public interest groups, claims to innovate within the legal framework and for the public good.

The American doctrine of conscientious use of copyrighted works is promoted by the Google corporation and other companies as a solution to the problem of free access to documents that seem inaccessible to them. The doctrine tests the permissible limits of free use through numerous lawsuits, which mean huge costs to protect copyright holders.

The most famous example of this trend is the Google project for scanning books. In April 2016, the scanning of documents from library holdings as executed for many years by the Google corporation was deemed legal by a unanimous decision of the US Court of Appeals, ending a 10-year battle.

Few copyright laws have been adopted in the United States recently, but one of them is quite important, that is, the Music Modernization Act, which combines three related draft laws and clarifies the legal problems of music and audio recordings in relation to new technologies, in particular to streaming. In addition, the United States Copyright Office regularly issues comments and recommendations on dealing with the well-known Copyright Law in the digital age (Digital Millennium Copyright Act, DMCA). The problem of copyright registration is being actively discussed.

On May 21, 2020, the US Copyright Office released the first full action report on the law about copyrighting in the digital age $(D M C A)$. The report is based on the results of 92000 written comments, five round tables, and decades of judicial practice. The office concluded that there is a bias in favor of technology companies in the $D M C A$ and that changes need to be made in favor of copyright holders [3].

The law about copyrighting in the digital age that was enacted by the U.S. Congress in 1998 updated American legislation on copyrighting, given the important interaction between copyrighting and the Internet. One of the purposes of this law was to take the growth of websites and Internet service providers that host user-generated content during those years into account. Sometimes such content violates the copyright of a third party and it was necessary to understand and decide who would be responsible for this. The idea was to respect the rights of creators while keeping the Internet working.

The 1998 law introduced three major updates:

(1) creating protection for online service providers in some cases where their users infringe on a copyright, including notification and content removal systems (notice-and-takedown system), which will allow 
copyright holders to inform providers about infringing material in order to remove it from access;

(2) encouraging copyright holders to provide wider access to their work in digital format by providing legal protection against unauthorized access to these works (for example, by stealing passwords or bypassing encryption systems);

(3) introduction of the responsibility for providing false information about copyrighting (for example, names of authors and copyright holders, and titles of works), failure to inform, or changing this information in certain circumstances.

This law provided so-called safe harbors, which are designed to balance two objectives: (1) to prevent potentially large economic losses for online service providers from possible liability for copyright infringement by users and (2) to protect copyright holders from the threat of rampant widespread violation of their rights in the online environment.

However, according to the report of the United States Copyright Office, the balance has not yet been reached. Office etc., concluded that the law creates an advantage for technology companies. It recognizes that online service providers are unable to track every one of the millions of posts by users for copyright infringement, thus placing the burden of tracking possible infringement on copyright holders.

To address the current imbalance in the implementation of the 1998 Act, and to better take the technological advances of the 21 st century into account, the Office offers several recommendations, including: (1) narrowing the responsibility of online service providers, (2) strengthening deterrents to copyright infringement, and (3) clarifying certain concepts and making procedural modifications.

The U.S. Copyright Office plans to create a new website: copyright.gov/DMCA for educational and practical purposes, and a U.S. Senate committee plans to draft amendments to this Act by the end of 2020 .

In Germany, small and independent publishers may be hit hard by the country's Supreme Court ruling in a 2012 lawsuit by the author and copyright specialist Martin Vogel (Martin Vogel) adopted in 2017, on the redistribution of royalties for the reprinting of literature between authors and publishers. Instead of the previous $70-30 \%$ formula in favor of the publishers, the government decided to divide the royalties 50 to $50 \%$, since the authors have the original copyright and this right was transferred to the publishers by contract. This decision can lead to large fines, and to bankruptcy of many small German publishing houses and their leaving the market [4].

In the UK, copyright legislation was quite radically reformed a few years ago; it is now ahead of the whole of Europe. As a result of the country's exit from the European Union, it is predicted that without the UK, the voice of content creators will be weaker, as Britain is a strong defender of the creative industry.
At the Roundtable on Copyrighting organized by the State Public Scientific and Technical Library of Russia together with the British Library we learned more about the major changes in copyrighting in the UK in 2014. Legally enacted copyright exceptions were a compromise between general public libraries and publishers and created legal certainty.

Recently, the education and research policy of the government of the UK has focused on four priorities: open access to research, copyrighting, transparency (i.e., opening up data from the government of the UK for public viewing), and Big Data; they all have a great influence on the work of the British Library.

In 2014, the UK enacted five key copyright exceptions in legislation:

- making digital copies of audio and film works for preservation purposes has become legal;

- the fair use principle (fair dealing) has been extended to noncommercial and private research and allows one to copy audio works and films, including with the help of a librarian or curator;

- digitization of the analogue collections of the British Library is permitted, provided that the digitized product is available from computer terminals in the library premises;

- deep analytical processing of text and data is allowed (text and data mining) for noncommercial and research purposes in legally acquired resources without obtaining an additional license;

- the British Library and its readers are entitled to apply the limitations and exceptions to copyrighting in the United Kingdom, regardless of contracts with publishers and suppliers.

We note briefly that the fair use concept and fair use of copyrighted works are similar but not identical. Both terms refer to a situation where the use of a work does not require permission or a license from the copyright holder. British and international legislation of the Commonwealth of Nations contains explicit named exceptions to copyrights. Some of them require compliance with the honest purpose of using the work, hence the name fair dealing and exceptions apply only then. Such cases include nonprofit academic research and personal research work, criticism and peer review, current affairs reporting and use for illustration, citation, parody, or caricature.

The exceptions for the fair use of works in this legislation creates certainty but the fair use of works doctrine in the United States is broader and more flexible. When determining the fairness of the use of a work, four factors are taken into account: the purpose and nature of the use, the nature of the work, the extent and significance of the borrowing, and the effect of the use on the potential market value of the work. The American concept allows many actions to be considered as completely legitimate; however, it is difficult to 
assess the listed factors, and many cases of fair use of works are heard in the American courts.

In the UK, in response to proposals for copyright reform, an innovative decision on orphan works was adopted by law, namely: a new licensing scheme allows users to apply for a nonexclusive license to use an orphan work for commercial and noncommercial purposes. It should be recalled that according to the European Union directive on orphan works that are subject to a fair search by the copyright holder, it was possible to publish material for noncommercial purposes. A new exemption, introduced in the United Kingdom in October 2014, allows cultural organizations to digitize written, cinematic, audiovisual, and sound works and present them on their websites for noncommercial use. The British Library obtained this opportunity and began to actively use it. The right to post orphan works on her website has been given to it for 5 years.

In Europe, legislation is structured primarily in the interests of copyright holders, and participants in the Digital Single Market generally support the status quo. At the end of March 2019, the European Parliament adopted the controversial European Digital Market Directive and in April it was approved by the Council of Europe [6]; this is in fact a revised Copyright Directive that has been outdated since its adoption in 2001. The purpose of the new Directive is to modernize copyright legislation, protect authors and creators, and create conditions for a flourishing European culture.

In general, the Directive implies strengthening the rights of publishers and copyrights in general and facilitating the process of licensing content. In particular, the focus is on better countering piracy. At the same time, greater opportunities for access to resources for libraries, museums, and archives are emerging; there is a "British" exception for libraries, that is, the data mining capability. As stated in the Directive, all European scientific organizations will be able to perform text and data mining in resources to which they have legal access. This addresses the issue of news publishers whose products (news) are widely copied on the Internet without due remuneration; the Directive proposes that websites pay a fee, like a copyright fee, in exchange for the inclusion of small fragments (snippets) of news with a link to the original news article. With regard to open access and open science, the Directive provides access but it is not free. Opening data is good for advanced technologies, for artificial intelligence, but it should not mean confiscation or loss of rights.

The Directive places particular emphasis on the creation of a single European digital market and the cross-border use of copyrighted material. The directive came into effect on June 7, 2019 and member countries have 2 years to introduce its provisions into their national legislation.
One of the significant events that took place in international copyright law was the signing of the Marrakesh Treaty to Facilitate Access for the Blind, Visually Impaired, or Otherwise Print Disabled. The Treaty was adopted at a conference held on June 1728, 2013 in Marrakesh, Morocco; it entered into force on September 30, 2016 after it was signed by 75 countries. Russia ratified the treaty in September 2017.

The Marrakech Treaty is part of a body of international copyright treaties administered by the World Intellectual Property Organization (WIPO). It has a humanitarian and a social dimension; its main purpose is to establish a set of binding limitations and exceptions.

An international treaty requires contracting parties to include in their national law provisions allowing the reproduction, distribution, and delivery of published works in accessible formats. It also reflects provisions on the cross-border exchange of these works in accessible formats between organizations that serve the blind, visually impaired, or print disabled. At the same time, the contract will provide guarantees to authors and publishers that this system will not expose their published works to the risk of misuse or distribution.

G.P. Ivliev, the head of the Federal Service for Intellectual Property, noted that the long-awaited text of the Marrakesh Treaty is an important political signal to the entire international community and to all persons in need of equal access to artistic and scientific works [7].

The International Federation of Library Associations and Institutions (IFLA), together with the World Council of the Blind, has been involved in the preparation of materials and advocacy for exceptions that are the essence of the Marrakesh Treaty, and together with the organization Electronic Information for Libraries eIFL, has created a practical guide for librarians to implement its provisions [8].

As a long-term member of the IFLA Committee on Copyright and Related Rights (IFLA CLM), one of the authors of this article has been involved in discussions on providing broader exceptions and limitations to copyright law for libraries, and not just special ones. Representatives of the IFLA CLM committee have worked for several years in negotiations at WIPO advocating for the interests of libraries; it is interesting that for the first time an exception from the legislation regarding the possibility of issuing the blind and visually impaired copies of works at home that were created in special formats were discussed at the meeting of the Committee. This was supported by the IFLA and included in proposals for discussion at WIPO.

IFLA monitors the implementation of the Marrakesh Treaty by countries around the world and publishes a report, the Marrakesh Monitoring Report, regularly [9]. It tracks which countries have acceded to the Treaty, which have ratified it, which have implemented its provisions in law and practice, and which 
may have surpassed them. Some governments may implement procedures to facilitate access to information for people with other disabilities (e.g., deaf people).

The newest Marrakesh Monitoring Report, dated March 2020, states that the Russian Federation is in line with the global trend of transforming copyrighting in the digital world.

In the Civil Code of the Russian Federation, h. IV (Civil Code of the Russian Federation) there is article 1274 , which contains positions concerning the provision of access to the products of intellectual activity for persons with physical disabilities, in particular those with visual impairments. This is allowed without the consent of the author or other copyright holder and without payment of remuneration, but with the obligatory indication of the name of the author, whose work is used, and the source of borrowing. "The creation of copies of lawfully made public works in formats intended solely for use by the blind and visually impaired (in Braille and other special methods), as well as the reproduction and distribution of such copies without the purpose of making a profit are allowed without the consent of the author or other owner of the exclusive rights and without payment of remuneration to him, but with the obligatory indication of the name of the author, whose work is used, and the source of borrowing. Libraries can provide the blind and visually impaired with copies of works created in special formats for temporary free use, as well as by providing access to them through information and telecommunication networks. The scrolling of special formats as well the scrolling of libraries that provide access through information and telecommunication networks to copies of works created in special formats, and the order the provision of such access, is determined by the Government of the Russian Federation. Any further reproduction or making a copy of the work available to the public in a different format of is not allowed."

\section{COPYRIGHTING, LIBRARIES, AND PUBLISHERS}

The relationship between copyrighting and library services touches on the underlying problems of intellectual property theory, the relationship between the creative individual and society. It is no coincidence that national copyright laws tend to contain separate clauses on limitations and exceptions to copyrights as they apply to libraries.

As the use of electronic documents expanded, copyright holders became increasingly dissatisfied with the application of exceptions to copyright laws, especially library privileges, and began to question whether exceptions were necessary at all when working with electronic documents. As noted in a statement by the International Federation of Reproduction Rights Organisation (IFPRO): "Reprographic rights organizations, authors, and publishers fully agree that free use of electronic (digital) documents, including under library privileges, should be carefully reviewed. The privileges adopted in the environment of analog documents cannot simply be transferred for use with electronic documents" [4]. The ease with which digital documents can be distributed and reproduced presents a challenge for electronic rights holders: they feel that their profits are threatened if just one purchased copy can be reproduced with excellent quality an infinite number of times.

Publishers often use international book fairs and exhibitions, such as those in London and Frankfurt, to defend their position. The keynote speech at the 2017 London Book Fair Seminar by Mr. William Bowes, executive officer of the Cambridge University Press and Chairman of the International Council of the Publishers Association, can be a kind of manifesto for publishers. Here are some of its provisions.

(1) Publishers do not understand and perceive copyrighting (copyright) as a monopoly. Copyright has and should have boundaries, like all intellectual rights. Publishers recognize the public interest behind:

(a) exceptions, including educational;

(b) threshold originality;

(c) time constraints.

(2) Publishers recognize that copyrighting is hard to understand and difficult to manage, and they stand ready to help governments address these challenges, which will only get more complex as digital technologies are introduced.

(3) Publishers also understand that the breadth and quality of documents required to fuel the knowledge economy takes time and investment. There should be no damage to the economic interests of authors and content creators.

(4) Politicians feel the risks of limiting access to the information that is created, but they do not feel the risks of limiting the emergence of new information and knowledge, which may arise if authors' property rights are infringed.

(5) There should be enough economic rights to solve social problems.

The social challenge is to support education by creating and distributing high quality materials. Publishers believe this can be achieved by supporting:

- editorial impartiality that is not subject to political influence;

- fair pay for work done honestly;

- access to high quality education;

- understanding the value of high quality teaching materials;

- the art of book publishing, which organizes, and improves teaching materials;

- high literary and cultural standards; 
- a worldwide system for the exchange of knowledge, education, and research.

\section{Rising Exceptions to Copyright Law and an Anti-Copyright Climate}

Any action gives rise to opposition. On the one hand, rightholders complain about the expanding exemptions from legislation and argue that the fair use concept has become free use, on the other hand, the application of the concept of open access is increasing in the world and examples of copyright exceptions are multiplying

The modern trend is "everything for the consumer." The focus of politics is the "democratization of knowledge" and ensuring access of as many people as possible to this rich (and, as it seems to politicians, inexhaustible) source of natural resources of mankind. Fair use is understood as fair for the consumer, but is it fair for the author? The question is raised over and over again of whether the now widespread opinion is correct that literature, including educational literature, should be free. Schools and universities pay for space, furniture, and teachers, so why should books be free?

The fundamental principles of copyrighting are increasingly challenged by those who do not want to pay to access a document that they can often download free from the Internet. This model is unsustainable if we want the creative economy to continue to develop. Free use of protected works does not ensure sustainable development. Perhaps one should not hope for constant change in copyrighting and its transformation into something that does not correspond to its original purpose. Copyright was created to stimulate and reward creativity, while providing society with the works that it needs. Traditionally, copyrighting and above all the right to copy a work, is the ownership of the creator of the document and those who invested in its creation. Copyrighting allows them, within certain limits, to control how the creative work is used and how it is paid for. This is important because it stimulates the growth of creativity. An ecosystem built on respect for rights supports the creation and production of high quality documents for the benefit of society as a whole.

\section{New Dimensions of Intellectual Property Copyright Education in the Digital World}

Calls to open access to knowledge and information often face problems related to the protection of intellectual property rights, and often this is not due to the difference in positions of the parties, but due to the complexity of the topic and the difficulty of taking all aspects into account. Therefore, education and training on copyrighting in the digital world is essential.

After serious research, copyright experts at Columbia University (United States) came to the conclusion that professionals and society in general welcome the creation of a virtual copyright education center that would offer help them in person or via the Internet in their daily work, when solving complex issues related to copyrighting [10]. These questions include:

- digitization/reformatting of the resources of libraries and archives and all institutions of cultural heritage for accessibility and preservation;

- digitization of primary sources to improve discoverability and expanding accessibility;

- online scientific communication and open access;

- educational use of copyrighted material;

- authors' rights;

- repatriation of rights from publishers;

- management of intellectual property of employees and teachers working in an institution;

- the development of metadata describing rights and the need to indicate the source, author, and rights data for online materials;

- related legal issues such as contract law, public, and private rights, how they relate to copyrighting, and how they form the basis for the moral rights that are part of copyrighting;

- scientific data, datasets, and related copyright issues;

- licensing, as well as Creative Commons licenses.

There are three main reasons that it is important to address copyright issues in cultural heritage institutions.

(1) Consistent practices in documenting and communicating rights and primary source information for digital materials can help democratize science. In the presence of metadata containing a description of the material and information about rights, scientists will be able to access more material and understand how they can use it.

(2) Establishing the reliability and authority of materials: this an ongoing problem for scholars and readers, especially in the online environment. It is often difficult to determine, with some probability, the reliability of materials out of context, or materials without an indication of the source and ownership. The sloppy practice of communicating scientific rights, as opposed to formal and standardized practice developed in a natural way, is probably in line with the informality of communication in the online environment. The digital age poses questions for academics related to scientific communication, authorship, provenance, and context. Where did this online material come from? Who created it? Is there a primary source that can be verified? How can the material be used and in what context? Can this material be legally shared for scientific purposes and knowledge dissemination? Can the materials be used for educational and scientific purposes? Finally, who owns the rights? 
(3) Copyright issues are often central to preservation and accessibility. This is especially true in the context of the streaming use of materials in scientific purposes: in a situation where scientists communicate their research through a variety of online platforms and communications, there are many issues related to copyrighting. The limits of application of liability, rights, permitted and unauthorized use copyrighted works continue to be tested in an increasingly complex environment.

\section{COPYRIGHTING \\ AND THE CORONAVIRUS PANDEMIC}

The problems caused by the danger of the new SARS-Cov-2 coronavirus infection have not bypassed the copyrighting area. On the contrary, in connection with the closure of many organizations for physical visitation and the widespread transition to electronic means of transmitting information, remote work, training, and communication, new difficulties and questions have arisen.

During normal times, students and teachers could personally come to the library or to a lecture and access to educational resources would not require a license. However, in times of crisis, there are no resources, no time, or legal expertise to obtain remote digital access rights to all the resources required in the educational process.

Therefore the Association of European Scientific Libraries LIBER (Ligue des Bibliothèques Européennes de Recherche) believes that Europe must take urgent action on copyright law to support distance learning and distance research during the coronavirus pandemic. The European Commission should issue urgent guidance to enable academics, educational institutions, and libraries to fulfill their educational responsibilities during the COVID-19 pandemic and provide remote services for the use of copyrighted material without fear of prosecution. [12]

LIBER encourages, in cases where the existing general licenses do not apply to specific organizations, allowing the following activities:

- delivery of complete documents to specific individuals;

- remote access to e-books, whose use is currently limited to the territory of the library/educational institution, for scientific purposes and for specifically named individuals;

- use of copyrighted works in online learning in the form of broadcast or pre-recorded educational activities intended exclusively for schoolchildren, students, and academics;

- reading stories/books in public libraries for webcasting.

This commitment is intended to be temporary and will only apply during the closure of schools, libraries, and universities due to the pandemic, or until the publisher or author cancels the commitment.

In addition to the pressing goals of the current pandemic, LIBER believes in longer-term measures:

- international and national copyright law should take the public interest into account during medical, environmental, or economic crises;

- The COVID-19 crisis highlights the importance of free and unhindered access to information and the need to move to open access as soon as practicable.

\section{CONCLUSIONS}

Considering the transformation of copyrighting in the context of the emergence of new information technologies and new circumstances allows us to conclude that copyrighting is not getting easier in the digital age.

(1) Digital transformation is a multidimensional process, a phenomenon much broader than the modernization of technology. Digital transformation is primarily about business models, processes, people, and culture.

(2) In our age, when everyone can become a creator, authors, including scientists, lack deep knowledge in the field of copyrighting. The contradictions between the desire of authors to provide the widest possible access to their work and the desire to maintain control over the future of their work continues unabated.

\section{CONFLICT OF INTEREST}

The authors declare that they have no conflicts of interest.

\section{REFERENCES}

1. Shrayberg, Ya.L., Information and documentary space of education, science, and culture in current conditions of digitalization of society, Ezhegod. dokl. Pyatogo Mezhdunar. prof. foruma "Krym-2019" (Annual Reports, Fifth Int. Prof. Forum "Crimea-2019"), Moscow: GPNTB Ross., 2019.

2. Shrayberg, Ya.L., Formation of a single knowledge space based on a network information infrastructure under conditions of the advancement and development of the modern digital economy, Ezhegod. dokl. Chetvertogo Mezhdunar. prof. foruma "Krym-2018” (Annual Reports, Fourth Int. Prof. Forum "Crimea-2018”), Moscow: Gos. Publ. Nauchno-Tekh. Bibl. Ross., 2018.

3. Kuzucan, A.U.S., Copyright Office: DMCA Is "Tilted Askew," Recommends Remedies for Rightsholders, JD Supra, Aug. 7, 2020. http://www.jdsupra.com/legalnews/u-s-copyright-office-dmca-is-tilted-27220/. Accessed October 28, 2020.

4. Zemskov, A.I. and Shrayberg, Ya.L., Avtorskoe pravo v bibliotekakh, nauchno-issledovatel'skikh i uchebnykh zavedeniyakh: Uchebno-prakticheskoe posobie (Copyright in Libraries, Research, and Educational Institutions: Educational and Practical Guide), St. Petersburg: Professiya, 2020. 
5. Hollaar Lee, A., Copyright of digital information, in Legal Protection of Digital Information, Washington, DC: BNA Books, 2014, ch. 3. http://digital-law-online.info/lpdi1.0/treatise33.html/. Accessed November 2, 2020.

6. Shaping the Digital Single Market: Strategy 2014$2019 . \quad$ https://ec.europa.eu/digital-single-market/en/shaping-digital-single-market. Accessed June 20, 2020.

7. Press Conference in RIA Novosti on the Topic "Marrakesh Treaty to Facilitate Access to Published Works by Visually Impaired Persons" with the participation of State Secretary - Deputy Minister G. Ivliev, RIA Novosti, Moscow, July 2, 2013. https://culture.gov.ru/about/advisory_authorities/obshchestvennyy_sovet/broadcast-meetings/video_archive/presskonferentsiya-v-ria-novosti-na-temu-marrakeshskiydogovor-o-rasshirenii-dostupa-k -knigam-lits-snarusheniyami-zren/. Accessed August 15, 2020.

8. Coates, J., Felsmann, C., Hackett, T., et al., Getting Started. Implementing the Marrakesh Treaty for Persons with Print Disabilities: A Practical Guide for Librarians, Owen, V., Ed., Univ. of Toronto, 2018. https://www.ifla.org/files/assets/hq/topics/exceptions-limitations/ getting_started_faq_marrakesh_treaty_a_practical_gu ide_for_librarians_2018_en.pdf.

9. Implementing the Marrakesh Treaty: Monitoring Report, 2020. https://www.ifla.org/publications/node/81925. Accessed November 12, 2020.

10. Pantalony, R.E. and Schonfeld, R.C., Copyright Education in Libraries, Archives, and Museums: A 21st Century Approach: A Summary Report of Roundtable Discussions at Columbia University, New York, Jan. 22, 2020. http://sr.ithaka.org/?p=312596. Accessed June 8, 2020.

11. Volkova, K.Yu., Zemskov, A.I., and Shrayberg, Ya.L., The book market in the digital age: What libraries need to know (based on materials from the 2019 London Book Fair and other events), Nauchn. Tekh. Bibl., 2020, no. 6 , pp. 49-68.

https://doi.org/10.33186/1027-3689-2020-6-49-68

12. Volkova, K.Yu. and Shrayberg, Ya.L., Analysis of trends in the development of modern library and information infrastructure in the context of the ongoing pandemic (review of materials from foreign professional publications), Nauchn. Tekh. Bibl., 2020, no. 11, pp. 15-32. 